\title{
Study on Characteristics of Tensile Strength of Concrete Considering Temperature Dependence in Mass Concrete Structures
}

\author{
Hiroki Izumi ${ }^{1}$, Juniti Arai ${ }^{2}$, and Toshiaki Mizobuchi ${ }^{1}$ \\ ${ }^{1}$ Student of master course, Department of Civil and Environmental Engineering, Hosei University Graduate School, Japan \\ ${ }^{2}$ Student of doctoral course, Department of Civil and Environmental Engineering, Hosei University Graduate School, Japan \\ ${ }^{3}$ Professor, Department of Civil and Environmental Engineering, Hosei University, Japan
}

\begin{abstract}
It is important to grasp mechanical and thermal properties in order to verify the possibility of thermal cracking. In this study, for the purpose of improving the accuracy of analysis in prediction of cracking caused by thermal stress, it was investigated that the direct tensile strength and thermal properties considering temperature history inside concrete member may be applied as a design values for the analysis of prediction of cracking caused by thermal stress. From results of these experiments, in early age, the direct tensile strength under mass curing which is considered temperature history inside concrete member is higher than the splitting tensile strength under standard curing. Which is cured under water of $20^{\circ} \mathrm{C}$. However, the direct tensile strength under mass curing is lower than the splitting tensile strength under standard curing after 7 days. At 28 days, the strength of former was about $20 \%$ lower than that of latter. In this study, the estimated formula on the strength development of the direct tensile strength was proposed. And the thermal expansion coefficient was estimated using measured values of strain and temperature. In this paper, it was reported that the test method of direct tensile strength considering temperature history inside concrete member was proposed and that the accuracy of analysis for the prediction of thermal cracking by using this method would be improved.
\end{abstract}

\section{Introduction}

Thermal cracking caused by volume change during heat hydration of cement is not only an initial defect but also greatly affects durability of concrete structures. The thermal stress analysis is carried out in order to predict and control thermal cracking at a design stage. However, the result of prediction of the thermal stress analysis may be different from results of stress behaviour in the existing structure since design values for analysis of requirement of mix proportions and environmental conditions can not completely reflect the conditions on site. Therefore, it is necessary to grasp mechanical and thermal properties of concrete exactly for improving of precision of the prediction for thermal cracking.

Since thermal cracking occurs when the tensile stress of concrete exceeds the tensile strength, it is particularly important to estimate the tensile stress and tensile strength definitely. Currently the tensile strength is required by the splitting tensile test. However, there is problem that the tensile stress do not occurs uniformly as a constraint stress is generated in the neighbourhood of loading point in the splitting tensile test. Further since specimens of standard curing under water of $20{ }^{\circ} \mathrm{C}$ are used, it cannot consider effects of temperature inside mass concrete member. Therefore, the tensile strength should be required by the direct tensile test using specimen considering the temperature history.

Tensile strength used for the design value is usually obtained from the compressive strength under water of $20{ }^{\circ} \mathrm{C}$. In this case, the tensile strength inside mass concrete member cannot be sufficiently evaluated since the tensile strength are estimated indirectly without considering effects of temperature history. Then, it is necessary to develop the test method for evaluating tensile properties inside mass concrete member.

In this study, the test method of direct tensile strength under mass curing which was conveniently obtained in site was proposed.

\section{Outline of Experiment}

\subsection{Case studied}

In this study, since the subject of investigation is mass concrete structure, six types of cement described in Guidelines for Control of Cracking of Mass Concrete 2016 published by Japan Concrete Institute (hereinafter referred to as JCI2016). For each cement, water to cement ratio was set to three levels of $45 \%, 50 \%$ and $60 \%$. In this experiment, the target slump was $8 \pm 1.5 \mathrm{~cm}$

* Corresponding author: hiroki.izumi.4f@stu.hosei.ac.jp 
and the target air content was $4.5 \pm 1.0 \%$. For each cement, unit content of water to satisfy the required quality of these fresh concrete was selected. Table-1 shows case studied.

Table 1. Case studied

\begin{tabular}{|c|c|c|c|c|}
\hline \multirow[b]{2}{*}{ kinds of cement } & \multirow[b]{2}{*}{ mark } & \multirow{2}{*}{$\begin{array}{c}\text { water cement ratio } \\
\mathrm{W} / \mathrm{C} \\
(\%)\end{array}$} & \multicolumn{2}{|c|}{ unit quantity $\left(\mathrm{kg} / \mathrm{m}^{3}\right)$} \\
\hline & & & $\begin{array}{c}\text { water } \\
\text { W }\end{array}$ & $\begin{array}{c}\text { cement } \\
\mathrm{C}\end{array}$ \\
\hline \multirow{3}{*}{$\begin{array}{c}\text { Normal Portland } \\
\text { cement }\end{array}$} & $\mathbf{N 4 5}$ & 45 & 157 & 349 \\
\hline & N50 & $\mathbf{5 0}$ & 158 & 316 \\
\hline & N60 & 60 & 154 & $\mathbf{2 5 7}$ \\
\hline \multirow{3}{*}{$\begin{array}{c}\text { Moderate Portland } \\
\text { cement }\end{array}$} & M45 & 45 & 157 & 349 \\
\hline & M50 & 50 & 157 & 314 \\
\hline & M60 & 60 & 157 & 262 \\
\hline \multirow{3}{*}{$\begin{array}{c}\text { Low-heat Portland } \\
\text { cement }\end{array}$} & L45 & 45 & 157 & 349 \\
\hline & L50 & 50 & 157 & 314 \\
\hline & L60 & 60 & 157 & 262 \\
\hline \multirow{3}{*}{$\begin{array}{l}\text { High-early-strength } \\
\text { Portland cement }\end{array}$} & $\mathbf{H 4 5}$ & 45 & 157 & 349 \\
\hline & H50 & 50 & 157 & 314 \\
\hline & H60 & 60 & 157 & 262 \\
\hline \multirow{3}{*}{$\begin{array}{c}\text { Portland } \\
\text { blast-furnace } \\
\text { cement B class }\end{array}$} & BB45 & 45 & 157 & 349 \\
\hline & BB50 & 50 & 154 & 308 \\
\hline & BB50 & 60 & 154 & 257 \\
\hline \multirow{3}{*}{$\begin{array}{c}\text { Fly ash cement } \\
\text { B class }\end{array}$} & FB45 & 45 & 157 & 349 \\
\hline & FB50 & 50 & 157 & 314 \\
\hline & FB60 & 60 & 157 & 262 \\
\hline
\end{tabular}

\subsection{Experimental method (Test method to evaluate thermal and mechanical properties using insulation container)}

\subsubsection{Method of investigation of mechanical properties}

The test device to evaluate thermal and mechanical properties using insulation container is shown in Figure1. The specimens of the both side in the device were used for the direct tensile test to investigate the tensile properties considering influence of temperature history inside mass concrete member. The direct tensile test was carried out at age of 3 days, 7 days, 14 days, 28 days using three specimens for each age. Layout of specimen used in the direct tensile test is shown in Figure-2. Loading rate is $0.05 \mathrm{~N} / \mathrm{sec}$ by using oil pressure type universal testing machine. Further the compressive test and the splitting tensile test were carried out at age same as the direct tensile test.

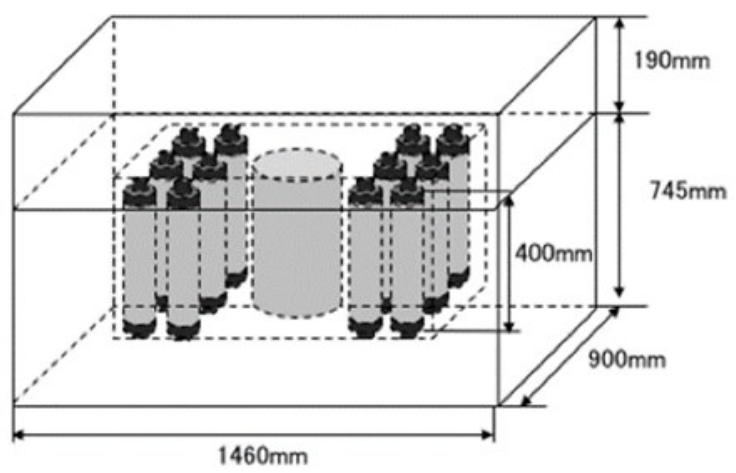

Figure-1 Layout of insulation container to evaluate thermal and mechanical properties conveniently
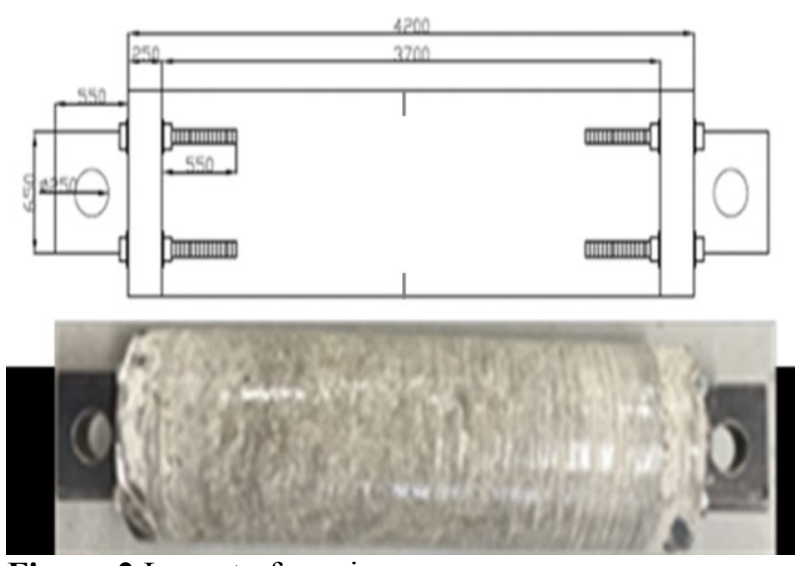

Figure-2 Layout of specimen

\subsubsection{Method of investigation of thermal properties}

The temperature history measured by the specimen, which is $\Phi 300$ millimaters $\times 400$ millimaters high, in the middle of the insulation container was used for the identification analysis by the temperature analysis to investigate insulation temperature rise properties. The formula described in JCI2016 were refed to estimate adiabatic temperature rise characteristics. And the relationship between the temperature amount of change and the strain amount of change used to calculate coefficient of thermal expansion.

\section{Results of experiment}

\subsection{Mechanical properties}

\subsubsection{The tensile strength}

Figure-3 shows one case of the result of comparison between the direct tensile strength development considering influence of temperature history inside mass concrete member and the splitting tensile strength development under water of $20{ }^{\circ} \mathrm{C}$ (BB50). The direct tensile strength is higher than the splitting tensile strength by the effect of temperature rise until age of 7 days. However, the splitting tensile strength is higher than the direct tensile strength after age of 7 days. Though it is different by a kind of the cement, the splitting tensile strength is higher the direct tensile strength at age of 28 days in most cases. There is $20 \%$ of differences between the splitting tensile strength under water of $20^{\circ} \mathrm{C}$ and the direct tensile strength considering influence of temperature history inside mass concrete member at age of 28 days.

Figure-4 shows example of the relationship between the splitting tensile strength under standard curing and the direct tensile strength considering influence of temperature history inside mass concrete member in all cases. The direct tensile strength considering influence of temperature history inside mass concrete member is lower than the splitting tensile strength under water of $20{ }^{\circ} \mathrm{C}$ in area of that the splitting tensile strength under water of $20^{\circ} \mathrm{C}$ is beyond $2 \mathrm{~N} / \mathrm{mm} 2$. And the direct tensile strength considering influence of temperature history 
inside mass concrete member is higher than the splitting tensile strength under standard curing in area of that the splitting tensile strength under water of $20^{\circ} \mathrm{C}$ is within 2 $\mathrm{N} / \mathrm{mm} 2$. This is because the direct tensile strength development given a temperature history is early.

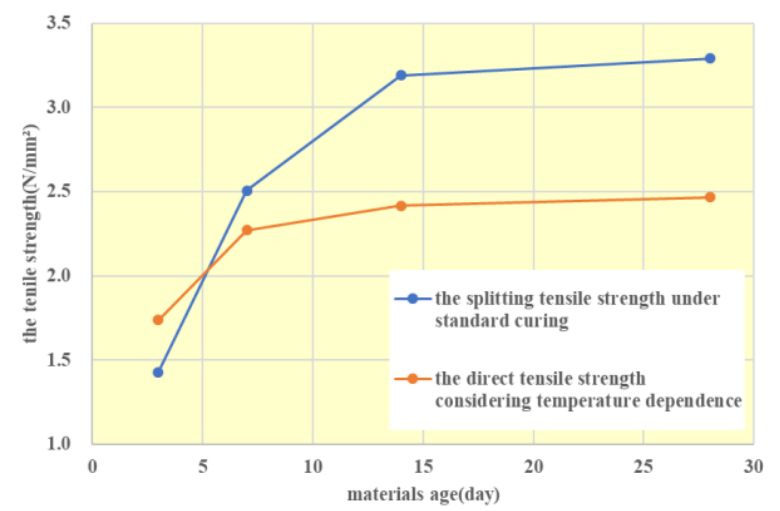

Figure-3 The result of comparison between the direct tensile strength development considering influence of temperature history inside mass concrete member and the splitting tensile strength development under water of $20{ }^{\circ} \mathrm{C}(\mathrm{BB} 50)$

Considering the mentioned above point, if the direct tensile strength considering influence of temperature history inside mass concrete member is near to structure body strength, it is evaluated the safe side for occurring cracking in area of that the tensile strength is within 2 $\mathrm{N} / \mathrm{mm} 2$ and the danger side for occurring cracking in area of that the tensile strength is beyond $2 \mathrm{~N} / \mathrm{mm} 2$.

\subsubsection{The estimated formula on the strength development of the direct tensile strength}

The direct tensile strength development coefficient equation (1) and the direct tensile strength development equation in management materials age 28 days considering influence of temperature history inside mass concrete member and a kind of cement are made based on the compressive strength development equation described in JCI2016 using the result of the direct tensile test.

$$
f_{s}\left(t_{e}\right)=\left(\left(t_{e}-S_{f}\right) /\left(A+B\left(t_{e}-S_{f}\right)\right) \times f_{t}\left(t_{n}\right)\right.
$$

here

$t_{\mathrm{e}}$ : effective material age(day)

$t_{n}$ : manegement materials age of cocrete under standard curing(day)

$\mathrm{f}_{\mathrm{t}}\left(\mathrm{t}_{\mathrm{e}}\right)$ : the direct tensile strength at effective materials age $t_{\mathrm{e}}$

A,B: coefficient expressed the tensile strength supported a kind of cement

$\mathrm{S}_{\mathrm{f}}$ : effective materials age expressed the hardening origin supported a kind of cement

$\mathrm{f}_{\mathrm{t}}\left(\mathrm{t}_{\mathrm{n}}\right)$ : the direct tensile strength at manegement materials age $t_{n}$

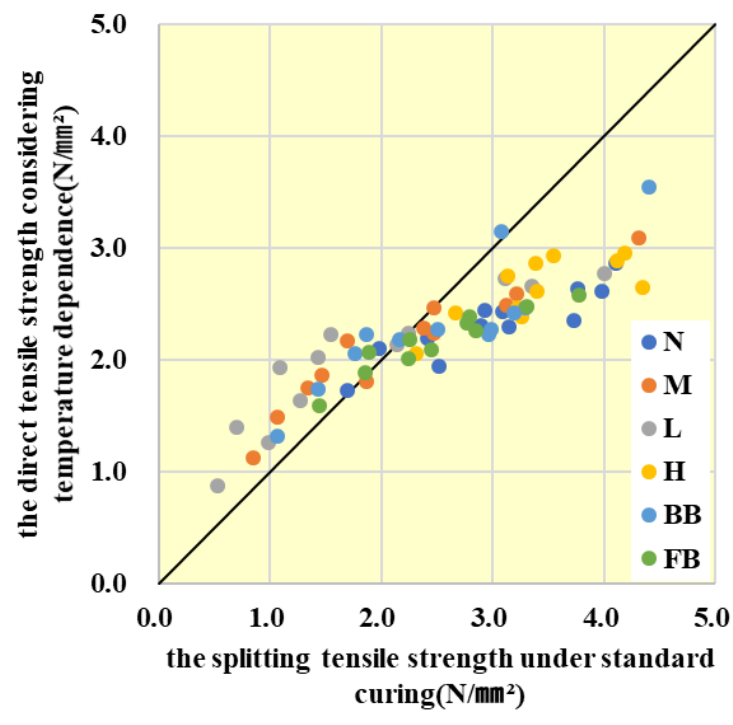

Figure-4 The relationship between the splitting tensile strength under standard curing and the direct tensile strength considering influence of temperature history inside mass concrete member in all cases

Table-2 shows each coefficient of the estimated formula on the strength development of the direct tensile strength and the estimated formula on the strength development of the direct tensile strength considering a kind of cement at manegement materials age 28 days made using result of the direct tensile test. The tensile strength of structure can be estimated directly by using the estimated formula on the strength development of the direct tensile strength.

Table-2 The coefficient of the estimatedequation of direct tensile strength development

\begin{tabular}{|c|c|c|c|c|c|c|c|}
\hline & \multicolumn{4}{|c|}{$A=\alpha 1+\beta 1(C / W) B=\alpha 2+\beta 2(C / W)$} & \multirow{2}{*}{$\mathbf{S}_{\mathbf{f}}$} & \multicolumn{2}{|c|}{$f_{t}=P 1+P 2(C / W)$} \\
\hline & al & B1 & $\boldsymbol{\omega} 2$ & B2 & & $\mathbf{P 1}$ & $\mathbf{P 2}$ \\
\hline $\mathbf{N}$ & 6. & 1.49 & 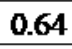 & 0.19 & 0.37 & 1.17 & .75 \\
\hline $\mathbf{M}$ & 11 & -2.25 & 0. & 0.70 & 0.42 & -0 & 1.42 \\
\hline $\mathbf{L}$ & 16.5 & -4.87 & 0.47 & 0.17 & 0.50 & 0 & 1.17 \\
\hline $\mathbf{H}$ & 16.6 & -6.52 & 0.96 & 0.00 & 0.30 & 2 & 14 \\
\hline B & 4.58 & 0.74 & 0.27 & 0.32 & 0.42 & -1.66 & 2.24 \\
\hline $\mathbf{B}$ & 8.40 & -2.30 & 0.75 & 0.10 & 0.47 & 1.85 & 0.32 \\
\hline
\end{tabular}

Figure-5 shows one case of the result of comparison between the tensile strength calculated using the estimated formula on the strength development of the direct tensile strength shown in Table-2 and using the estimated equation described in JCI2016(N50). the estimated formula on the strength development of the direct tensile strength made from the test result is nearer to the experimental value than that described in JCI2016. The tensile strength calculated by the estimated equation described in JCI2016 is overestimated by $20 \%$ generally. 


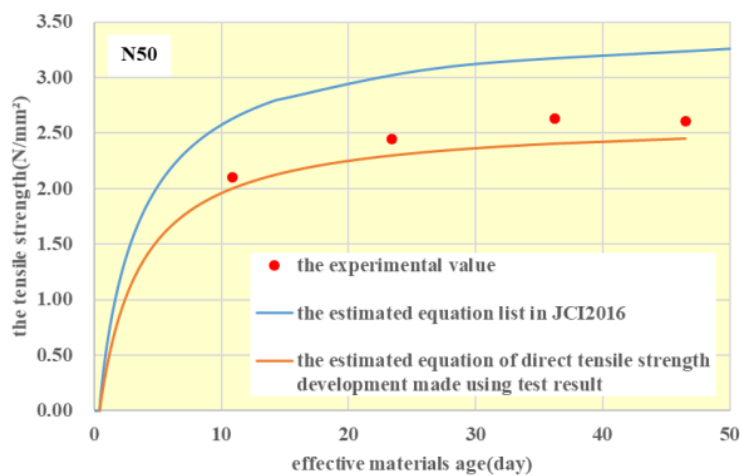

Figure-5 The result of comparison between the tensile strength calculated using the estimated formula on the strength development of the direct tensile strength shown in Table- 2 and using the estimated equation described in JCI2016(N50)

Figure-6 shows comparison between the experimental value and the tensile sterength calculated by using the estimated formula on the strength development of the direct tensile strength in all cases. Most case of the tensile strength caluculated by using the estimated formula on the strength development of the direct tensile strength accorded with the experimental value except a caseof Moderate Portland cement.

Caused by the result mentioned above, the possibility that could estimate the tensile strength of structure to some extent is found by the result of the direct tensile test using insulation container.

\subsection{Thermal properties}

\subsubsection{Insulation temperature rise properties}

Insulation temperature rise properties is estimated by the identification analysis by the temperature analysis using the results of temperature history. Figure-7 shows comparison between the quantity of end insulation temperature rise calculated by using the estimated equation described in JCI2016 and that of the experimental value in all case. The quantity of end insulation temperature rise calculated by using the estimated equation described in JCI2016 is about 20\% lower than that of the experimental value of insulation container regardless of a kind of cement and water cement ratio.

Figure-8 shows comparison between the experimental value of adiabatic type calorimeter and that of insulation container. Although there is little number of the cases, the experimental value of insulation container accorded with that of adiabatic type calorimeter.

Figure-9 shows comparison between coefficient $\alpha$ about the temperature rise speed described in JCI2016 and that of the experimental value. The experimental value of insulation container accorded with JCI2016 regardless of a kind of cement.

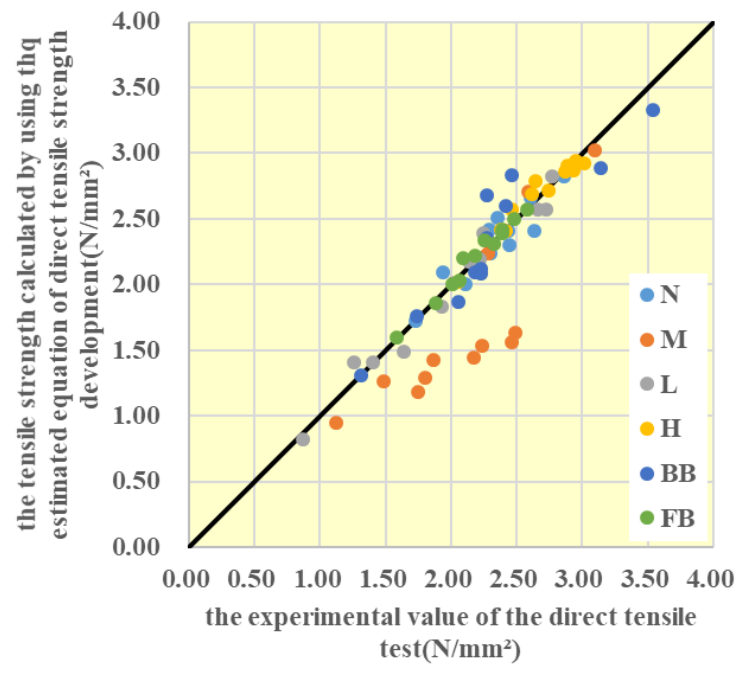

Figure-6 Comparison between the experimental value and the tensile sterength calculated by using the estimated equation of direct tensile strength development in all cases

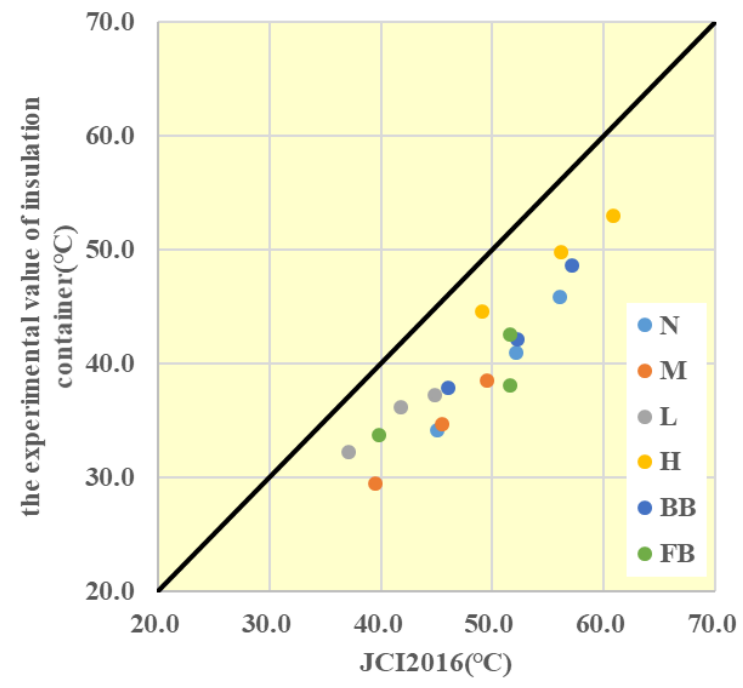

Figure-7 Comparison between the quantity of end insulation temperature rise calculated by using the estimated equation described in JCI2016 and that of the experimental value in all case 


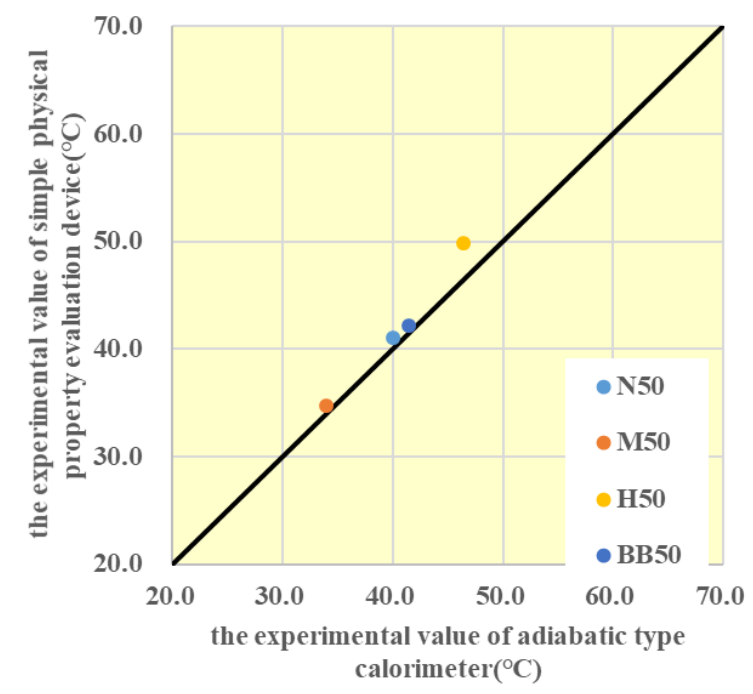

Figure-8 Comparison between the experimental value of adiabatic type calorimeter and that of insulation container

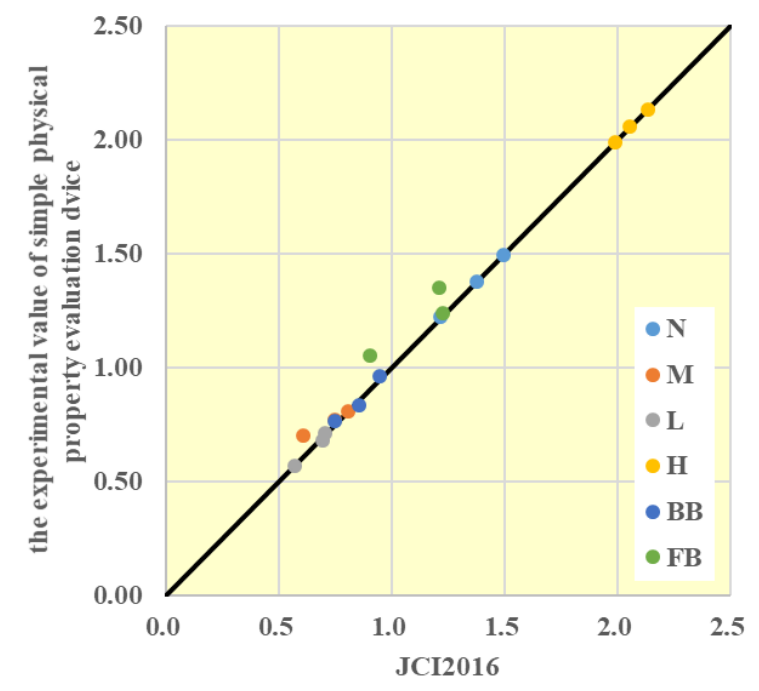

Figure-9 Comparison between coefficient $\alpha$ about the temperature rise speed described in JCI2016 and that of the experimental value

\subsubsection{Coefficient of thermal expansion}

Figure-10 shows one case of the relationship between amount change of temperature and that of strain provided by buried type strain meter. Although some hardening origins are different, temperature rise area and temperature descent area showed an approximately similar incline regardless of a kind of cement.

In this study, it is examined that coefficient of thermal expansion calculated by the experimental value is the apparent coefficient of thermal expansion included a self-shrinkage strain, because the experimental strain of test to evaluate thermal properties is including selfshrinkage strain. In this study, the apparent coefficient of thermal expansion is calculated by dividing part about the same an incline in temperature rise area and descent area into four sections which is temperature rise section (1), (2) and temperature descent section (1),(2). Table-3 shows the apparent coefficient of thermal expansion in each case. Although there is unevenness by a few water cement ratios, the apparent coefficient of thermal expansion is organized for every kind of cement.

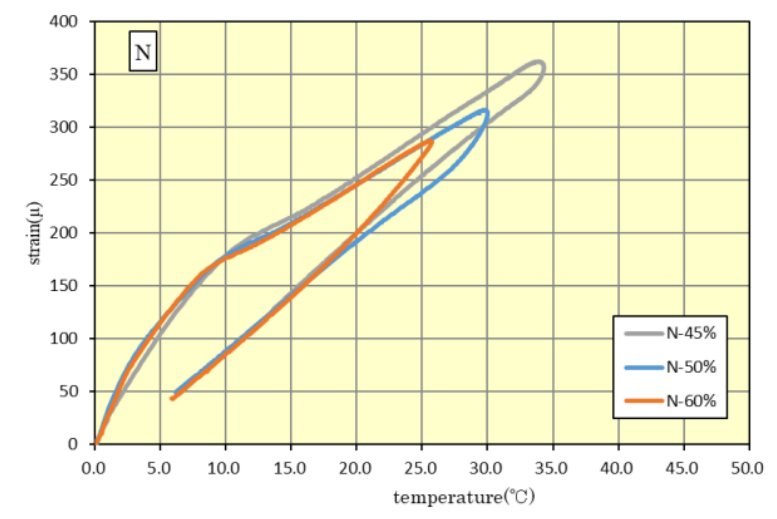

Figure-10 The relationship between amount change of temperature and that of strain provided by buried type strain meter

Table-3 The apparent coefficient of thermal expansion

\begin{tabular}{|c|c|c|c|c|c|c|c|c|c|}
\hline \multirow{3}{*}{$\begin{array}{c}\text { a kind } \\
\text { of } \\
\text { cement }\end{array}$} & \multirow{3}{*}{$\begin{array}{c}\text { unit } \\
\text { cement } \\
\text { content } \\
(\mathrm{kg} / \mathrm{m} 3 \\
)\end{array}$} & \multicolumn{8}{|c|}{ the coefficient of thermal expantion $\left(\mu /{ }^{\circ} \mathrm{C}\right)$} \\
\hline & & \multicolumn{2}{|c|}{$\begin{array}{c}\text { te mperature rise } \\
\text { are a(1) }\end{array}$} & \multicolumn{2}{|c|}{$\begin{array}{c}\text { te mperature rise } \\
\text { area(2) }\end{array}$} & \multicolumn{2}{|c|}{$\begin{array}{c}\text { temperature } \\
\text { descent area(1) }\end{array}$} & \multicolumn{2}{|c|}{$\begin{array}{c}\text { temperature } \\
\text { descent area(2) }\end{array}$} \\
\hline & & $\begin{array}{l}\text { experime } \\
\text { ntal value }\end{array}$ & $\begin{array}{c}\text { averag } \\
\text { e }\end{array}$ & \begin{tabular}{|l|} 
experime \\
ntal value
\end{tabular} & $\begin{array}{c}\text { averag } \\
\text { e }\end{array}$ & $\begin{array}{l}\text { experime } \\
\text { ntal value }\end{array}$ & $\begin{array}{c}\text { averag } \\
\text { e }\end{array}$ & $\begin{array}{l}\text { experime } \\
\text { ntal value }\end{array}$ & $\begin{array}{c}\text { averag } \\
\text { e }\end{array}$ \\
\hline \multirow{3}{*}{$\mathbf{N}$} & 349 & 18.19 & \multirow{3}{*}{19.88} & 7.13 & \multirow{3}{*}{7.18} & 23.54 & \multirow{3}{*}{20.45} & 10.76 & \multirow{3}{*}{11.07} \\
\hline & 316 & 20.31 & & 7.16 & & 20.98 & & 9.63 & \\
\hline & 257 & 21.14 & & 7.26 & & 16.84 & & 12.83 & \\
\hline \multirow{3}{*}{ M } & 349 & 7.70 & \multirow{3}{*}{10.31} & 6.43 & \multirow{3}{*}{6.63} & 15.52 & \multirow{3}{*}{14.68} & 10.85 & \multirow{3}{*}{11.6} \\
\hline & 314 & 10.48 & & 5.96 & & 16.21 & & 12.56 & \\
\hline & 262 & 12.76 & & 7.49 & & 12.32 & & 11.52 & \\
\hline \multirow{3}{*}{$\mathbf{L}$} & 349 & 5.51 & \multirow{3}{*}{10.03} & 4.17 & \multirow{3}{*}{5.06} & 16.50 & \multirow{3}{*}{13.61} & 16.40 & \multirow{3}{*}{14.22} \\
\hline & 314 & 9.79 & & 5.44 & & 13.84 & & 13.98 & \\
\hline & 262 & 14.79 & & 5.55 & & 10.50 & & 12.27 & \\
\hline \multirow{3}{*}{$\mathbf{H}$} & 349 & 12.93 & \multirow{3}{*}{12.97} & 3.90 & \multirow{3}{*}{5.14} & 9.66 & \multirow{3}{*}{5.04} & 11.53 & \multirow{3}{*}{11.05} \\
\hline & 314 & 13.99 & & 5.31 & & 3.12 & & 10.72 & \\
\hline & 262 & 12.00 & & 6.21 & & 2.34 & & 10.89 & \\
\hline \multirow{3}{*}{ BB } & 349 & 14.62 & \multirow{3}{*}{14.09} & 6.82 & \multirow{3}{*}{7.36} & 6.68 & \multirow{3}{*}{5.58} & 14.98 & \multirow{3}{*}{13.60} \\
\hline & 308 & 14.52 & & 7.94 & & 4.08 & & 13.69 & \\
\hline & 257 & 13.14 & & 7.34 & & 5.98 & & 12.13 & \\
\hline \multirow{3}{*}{ FB } & 349 & 11.16 & \multirow{3}{*}{11.68} & 6.88 & & 4.56 & & 12.23 & \\
\hline & 314 & 10.63 & & 6.86 & 6.93 & 23.88 & 13.09 & 12.29 & 12.29 \\
\hline & 262 & 13.25 & & 7.06 & & 10.82 & & 12.35 & \\
\hline
\end{tabular}

\section{Thermal stress analysis}

\subsection{Outline of Thermal stress analysis}

Thermal stress analysis was performed by using the experimental value. Figure-11 shows analysis model of Box Calvert. The analysis model is 10 meters in height, 10 meters in width, 1 meters of wall-thicknesses, 10 meters in construction length. The analysis model is a quarter model considering symmetry. The lower slab of 1 meter of thickness is cast in the first lift, and the sidewall and upper slab are cast in the second lift. It is set casting distance on 28 days.

The experimental value is used for the value for designs of thermal stress analysis. Besides the 
experimental value, for example properties of concrete and the ground, the value described in JCI2016 is used for the value for design of thermal stress analysis.

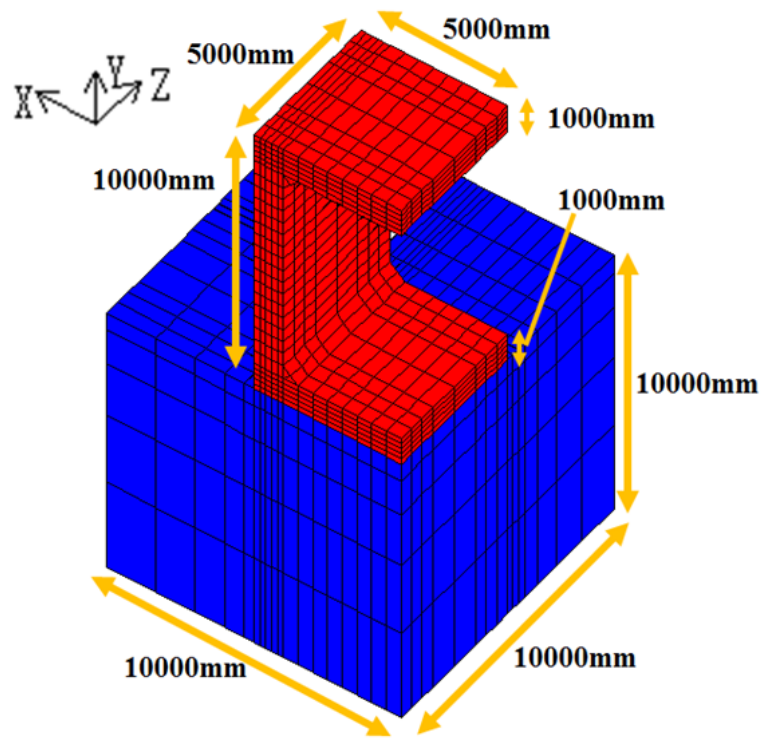

Figure-11 analysis model of Box Calvert

\subsection{Result of thermal stress analysis}

In this study, the direct tensile strength of the estimated equation by using result of the direct tensile test is used for tensile strength in thermal stress analysis. Figure-12 shows one case of analysis result of stress history(N50). The direct tensile strength of the estimated equation by using by using result of the direct tensile test is about $20 \%$ lower than the tensile strength of the estimated equation described in JCI2016 in the same way as the direct tensile test. It is thought there is reason of reflection of that the tensile strength inside mass concrete member is lower than that under standard curing as showed by the result of simple physical property evaluation test. The tensile strength development speed of the estimated equation not to through compressive strength is slower than that of the estimated equation described in JCI2016 in early age. It is necessary to reproduce real behaviour for strength development in early age by performing a lot of experiments. Therefore it is thought that the generation stress of the result using the direct tensile test is lower than that of JCI2016, because the quantity of end adiabatic temperature rise of the result of the direct tensile test is greatly less in comparison with the quantity of end insulation temperature rise described in JCI2016.

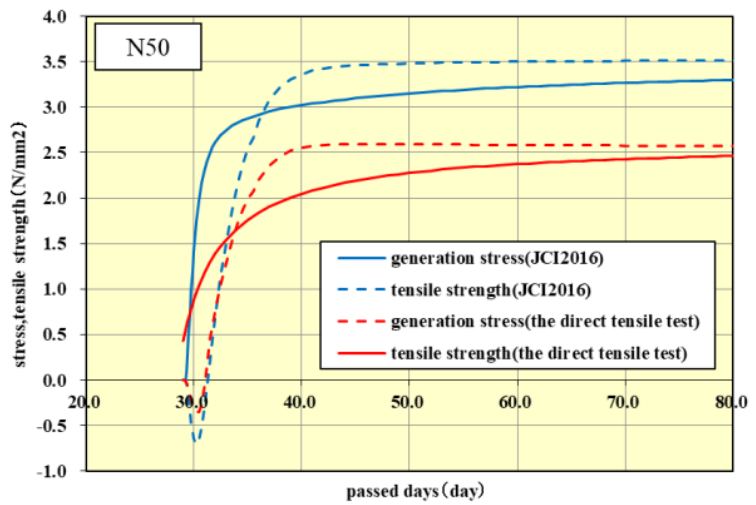

Figure-12 Analysis result of stress history(N50)

Figure-13 shows one case of analysis result of cracking index history(N50). The cracking index of the result of the direct tensile test is less than the cracking index described in JCI2016 up to approximately 0.1 . However the cracking index of the result of the direct tensile test accords with that described in JCI2016 as material age progresses. So the result described in JCI2016 evaluates outbreaking cracking in the danger side than the result of the direct tensile test.

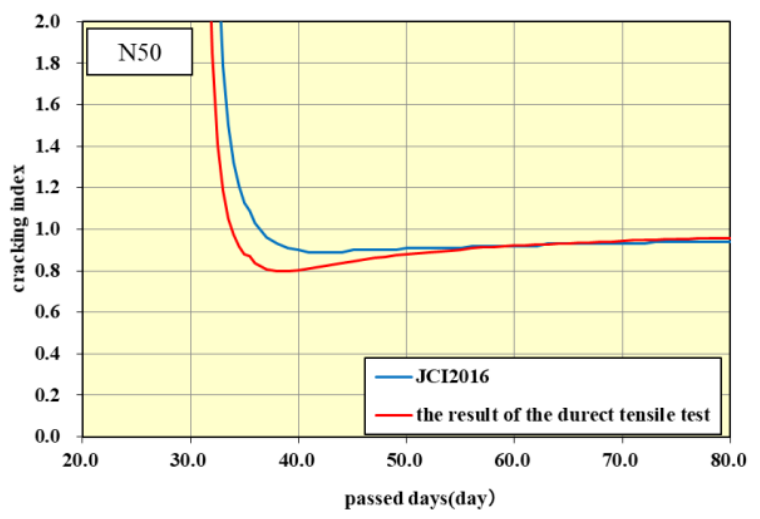

Figure-13 Analysis result of cracking index history(N50)

Figure-14 shows comparison between the cracking index described in JCI2016 and the cracking index of the result of the direct tensile test in all case. The cracking index of the result of the direct tensile test is great less in comparison with that described in JCI2016 in a kind of cement in a case of Moderate Portland cement and Lowheat Portland cement. In the area that is less than it of smallest cracking index to considered as a boundary line about having cracking outbreak or not 1.0 , the cracking index of the result of the direct tensile test is less than that described in JCI2016 around 0.1 in case of a kind of cement of Normal Portland cement, High-early-strength Portland cement, Portland blast-furnace cement B class and Fly ash cement B class. 


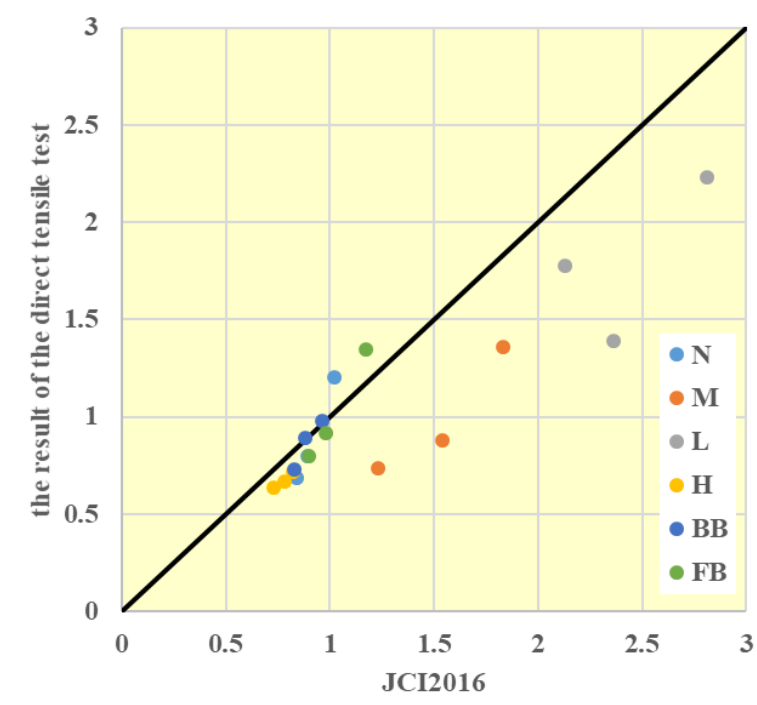

Figure 14 Comparison between the cracking index described in JCI2016 and the cracking index of the result of the direct tensile test in all case

Caused by the result mentioned above, when it is supposed that the direct tensile strength considering influence of temperature history inside mass concrete member is near to structure body strength, there is possibility to evaluate outbreaking cracking in the danger side by using the splitting tensile strength under water of $20^{\circ} \mathrm{C}$.

It is necessary to examine the modulus of elasticity having the need to distinguish the tensile strength and the compressive strength and the creep greatly influencing generation stress in early age which are value for design of thermal stress analysis to express structure body strength.

\section{CONCLUSION}

In this study, the direct tensile test using insulation container was conducted to investigate mechanical and thermal properties in mass concrete structure. The results are shown below.

1. In early age, the direct tensile strength under mass curing considering temperature history inside concrete member is higher than the splitting tensile strength under water of $20^{\circ} \mathrm{C}$. However, the direct tensile strength under mass curing is lower than the splitting tensile strength under standard curing after 7 days. At 28 days, the strength of former was about $20 \%$ lower than that of latter.

2. There is possibility to evaluate the tensile strength in the danger side for occurring cracking in area of that the tensile strength is beyond $2 \mathrm{~N} / \mathrm{mm} 2$.

3. The estimated formula on the strength development of the direct tensile strength was proposed made it possible to estimate tensile strength inside concrete member directly.

4. the test method of direct tensile strength considering temperature history inside concrete member was proposed and that the accuracy of analysis for the prediction of thermal cracking by using this method would be improved.
5. If the direct tensile strength considering influence of temperature history inside mass concrete member is near to structure body strength, there is possibility to evaluate outbreaking cracking in the danger side caused by result of the thermal analysis described in JCI2016 and that used experimental results.

\section{References}

1. T.Tunashima, R.Inoue, Y.Maki, T.Mizobuchi, The tensile properties of the concrete using various cement, Concerete engineering annual memoirs, vol32, No.1, 2010

2. N.Takeuchi, T.Muronoi, Y.Maki, T.Mizobuchi, Basic study on properties of evaluation of concrete using insulation container, Concerete engineering annual memoirs, Vol33, No.1, 2011

3. R.Senba, J.Arai, T.Hasegawa, T.Mizobuchi, Examination about critical limit of concrete cracks using various cement, Concerete engineering annual memoirs, Vol.37, No.1, 2015 